\title{
Optimization of Renewable Energy Resources in Hybrid Energy Systems
}

\author{
S. Surender Reddy \\ Department of Railroad and Electrical Engineering, Woosong University, \\ Daejeon-300718, Republic of Korea \\ E-mail: salkuti.surenderreddy@gmail.com
}

Received 14 April 2017; Accepted 30 June 2017;

Publication 18 August 2017

\begin{abstract}
This paper proposes the optimization of renewable energy resources (RERs) in the hybrid energy systems in a sustainable hybrid energy system. The behavior of renewable energy is uncertain and it is difficult for static optimization methods to optimize the uncertain non-stationary distributed energy resources in the hybrid system. A multi-objective based on the stochastic technique for optimizing total system losses and operating cost is formulated for the hybrid energy system. The proposed objective function aims to minimize the system losses and the total operating cost of RERs in different locations of the grid. In this paper, a next generation of grid connected RERs and load demand is proposed by considering the variability and uncertainty. Here, a robust stochastic approach is proposed by using the various probability distribution functions to represent the statistics of RERs. The simulation results of this paper handle the system operations under uncertainty. The proposed approach is tested on IEEE 37 node distribution system. The simulation results show the effectiveness of the proposed optimization approach in the hybrid energy system.
\end{abstract}

Keywords: Renewable energy, Optimization, Hybrid energy systems, Probability distribution, Uncertainty.

Journal of Green Engineering, Vol. 7, 43-60.

doi: 10.13052/jge1904-4720.7123

(c) 2017 River Publishers. All rights reserved. 


\section{Nomenclature}

$\mathrm{C}_{\mathrm{PV}} \quad$ Cost of power generation from solar photovoltaic (PV) generator.

$\mathrm{C}_{\mathrm{W}} \quad$ Cost of power generation from Wind Energy Generator (WEG).

DI Decision index.

$\mathrm{f}(\mathrm{v}) \quad$ Probability distribution function (PDF) of wind speed.

$\mathrm{I}_{\mathrm{jk}} \quad$ Branch current flows from bus $\mathrm{j}$ to bus $\mathrm{k}$.

$\mathrm{k} \quad$ Shape factor.

$\mathrm{L}_{\text {par }} \quad$ Line parameters (i.e., line impedances).

$\mathrm{P}_{\mathrm{mp}} \quad$ Maximum power output from solar PV unit.

$\mathrm{P}_{\mathrm{mp}, \mathrm{ref}} \quad$ Maximum power output under standard testing conditions.

$\mathrm{P}_{\mathrm{G}} \quad$ Active power injected at substation.

$\mathrm{Pn}_{\text {lim }} \quad$ Penetration level permissible for the system (approximately $0.30)$.

$\mathrm{P}_{\mathrm{DG}, \mathrm{j}, \max }$ Maximum permissible penetration per bus (approximately $10 \mathrm{MW})$.

$\mathrm{P}_{\mathrm{PV}, \mathrm{j}} \quad$ Real power output from solar PV unit installed at $\mathrm{j}^{\text {th }}$ bus.

$\widehat{\mathrm{P}}_{\mathrm{pv}, \mathrm{j}}^{\min } \quad$ Lower limit of active power output from solar PV generator installed at $\mathrm{j}^{\text {th }}$ bus.

$\widehat{\mathrm{P}}_{\mathrm{pv}, \mathrm{j}}^{\max } \quad$ Upper limit of active power output from solar PV generator installed at $\mathrm{j}^{\text {th }}$ bus.

$\mathrm{P}_{\text {wind,j }} \quad$ Active power output from WEG installed at $\mathrm{j}^{\text {th }}$ bus.

$\widehat{\mathrm{P}}_{\text {wind }, \mathrm{j}}^{\min } \quad$ Lower limit of active power output from the WEG installed at $\mathrm{j}^{\text {th }}$ bus.

$\widehat{\mathrm{P}}_{\text {wind, } \mathrm{j}}^{\max } \quad$ Upper limit of active power output from the WEG installed at $\mathrm{j}^{\text {th }}$ bus.

$Q_{G} \quad$ Reactive power injected at the substation.

$Q_{w i n d, j} \quad$ Reactive power output from the WEG installed at $\mathrm{j}^{\text {th }}$ bus.

T Temperature.

$\mathrm{T}_{\text {ref }} \quad$ Temperature for standard testing conditions $\left(\mathrm{T}_{\text {ref }}=25^{\circ} \mathrm{C}\right)$.

$\mathrm{W}_{1} \quad$ Weight component assigned to the total operating cost.

$\mathrm{W}_{2} \quad$ Weight component assigned to the total system losses.

$\gamma \quad$ Maximum power correction for temperature.

$\alpha \quad$ Scale factor. 


\section{Introduction}

Nowadays, with the increasing importance for environment, the renewable energy resources (RERs) are used to alleviate the climate change and desertification caused by the large amounts of $\mathrm{CO}_{2}$ emissions into the atmosphere [1]. And also to reduce the dependency on fossil fuels [2]. The national needs for efficient and flexible power grids encourage the development of advanced communication and optimization technologies in RERs. For the modern grid, several computational technologies are needed to design and study the long and short term energy independence based on RERs. To achieve this in a timely manner, research activities are needed to provide adequate modeling, and optimization techniques that accounts for variability and randomness in the hybrid energy system. Adequate modeling of RERs is needed to handle the variability and uncertainties of the loads to meet the generation and load demand. Also for optimal allocation of different types of renewable energy into the distribution network by minimizing the losses and operational costs. A probabilistic optimization technique which combines the variability of resources and load uncertainties includes network and security constraints is utilized.

Reference [3] presents the hybrid energy system to make optimum utilization of available renewable sources and also they become the cost effective by minimizing the per unit cost of generation. A multi-objective formulation to allow optimizing simultaneously both the annualized renewable energy cost the system reliability defined as the renewable energy - load disparity is proposed in [4]. Reference [5] proposes a micro grid (MG) model which integrates the power plants driven by RERs employing micro hydro and photovoltaic (PV) system which is connected to the utility grid. A multi-source hybrid power system which includes the RERs such as biomass, solar radiation as a primary source, and a battery is used to cover the emergency load, and a diesel generator for backup is presented in Reference [6]. An approach for optimization of the power generated from hybrid renewable energy systems to achieve the load of typical house as example of load is proposed in Reference [7].

The effect of variability in RERs on the optimal design and reliability of an integrated power system designed for off-grid mining operation using a twostage methodology is proposed in [8]. Reference [9] presents the optimum sizing, prefeasibility analysis, modeling, control aspects and reliability issues and also the application of meta-heuristic algorithms and game theory in a hybrid renewable system. A new optimization method called two-time 
steps re-calculation strategy is proposed in Reference [10], to handle the uncertainty. Reference [11] presents an approach for operations optimization to maximize their economic value based on market information and predicted renewable generation. Reference [12] presents a comprehensive review of various methods and techniques that are used to develop a successful energy management in hybrid renewable energy systems. A methodology to systematically formulate a hybrid system consisting the wind, solar and diesel generator as a backup resource as well as battery storage, from the preliminary design stage to the optimal operation is proposed in [13]. In Reference [14], a new approach is proposed to incorporate the uncertainties associated with RERs and load demand in sizing in the application of buildings with low to high renewable energy ratio. An optimal power generation and load management problems in off-grid hybrid electric systems with RERS is addressed in Reference [15].

Reference [16] proposes three objective functions, i.e., loadability, losses and cost for determining the optimal locations for each kind of RERs using mixed integer nonlinear programming. Reference [17] presents an up-to-date literature review on trends in optimization approaches used for the design and development of wind- solar PV based hybrid energy systems. The generation scheduling approach for a MG consisting of thermal generators, wind energy generators, solar PV systems, battery storage and electric vehicles is proposed in [18]. The discussion on motivation for Smart Grid development, the working definition and the tools for analysis and development of the Smart Grid is proposed in [19]. An economic dispatch (ED) model for the power system with thermal and wind generators is proposed in [20], where the probability of stochastic wind power is considered as a constraint. Reference [21] proposes a market clearing mechanism for wind-thermal power system including uncertainties in wind power and load forecasts. An energy and spinning reserve market clearing method for wind-thermal power system considering total cost and system-risk-level minimization as objectives is proposed in [22]. A genetic algorithm based search procedure is used in [23] to accomplish the adequacy assessment for power generating system including wind energy generators. Reference [24] proposes an approach to include the WEGs in the ED problem by considering the over-estimation and under-estimation of available wind power. A load dispatch model to minimize the emission due to oxides of nitrogen by taking into accounts both thermal generators and WEGs is proposed in [25]. The approach proposed in the present paper is examined on IEEE 37 node distribution test system and the test system data is taken from [26-27]. The proposed approach is coded in General Algebraic Modelling 
System (GAMS) [28], and it is solved using the CPLEX 11.2 solver (which is used to solve large scale MILP problems).

From the above literature review, it can be observed that there is a pressing requirement for developing new algorithms/mechanisms considering the stochastic behavior of Renewable Energy Resources (RERs). For the proposed integrated/hybrid energy system with several RERs and load demands with variability and randomness due to solar irradiation and wind speeds. This paper will help to address the variability of RERs and uncertainties of loads, which will help to improve system security, efficiency and reduce dependence on fossil fuels. The major contributions of this paper are presented next:

- Developed a next generation of grid connected RERs and load considering the uncertainty and variability.

- Developed a robust stochastic approach with RERs and load demand.

- Modeled wind and solar to account for variability and obtain a stochastic power output.

- Use of various PDFs to represent the statistics of the resources being evaluated. This will benefit the stochastic scheduling and power management overtime for generation load adequacy and security.

- Evaluate different optimization techniques that will endorse the study of optimal strategy of resource allocation to meet load demand and ensure system security.

The remainder of the paper is organized as follows: Section 2 presents the proposed problem formulation. The modeling of power output from solar PV and wind energy systems is described in Section 3. Section 4 presents the simulation results and discussion. Finally, the contributions with concluding remarks are described in Section 5.

\section{Problem Formulation}

A multi-objective based on the stochastic technique for optimizing total system losses and operating cost is formulated for the hybrid energy system. The proposed objective function aims to minimize the system losses and the total operating cost of RERs in different locations of the grid. Here, the multiobjective optimization problem is formulated using the weighted summation approach. There are two weighted components for the total cost of operation and losses for an $n$ bus power system with $m$ branches. The proposed objective function is formulated as, 
Minimize, Decision Index (DI)

$D I=W_{1}\left[\sum_{i=1}^{N_{G}} C_{G i}\left(P_{G i}\right)+\sum_{j=1}^{N_{W}} C_{W j}\left(P_{W j}\right)+\sum_{k=1}^{N_{S}} C_{S k}\left(P_{P V, k}\right)\right]+W_{2}\left[P_{\text {loss }}\right]$

where the total system losses $\left(P_{\text {loss }}\right)$ is expressed as,

$$
P_{\text {loss }}=\sum_{i=1}^{n}\left[\frac{r_{i}\left(P_{i}^{2}+Q_{i}^{2}\right)}{V_{i}^{2}}\right]
$$

The above objective function (i.e., Equation (1)), for sub-transmission or distribution networks is solved by including the following equality and inequality constraints:

(i) Recursive active power balance equation

$$
\begin{aligned}
P_{j-1}- & P_{j}-r_{j}\left(\frac{\left(P_{j-1}^{2}+Q_{j-1}^{2}\right)}{V_{j-1}^{2}}\right)+P_{p v, j}\left(t, \mu_{p v, j}, \theta_{p v, j}\right) \\
& +P_{w, j}\left(t, \mu_{w, j}, \theta_{w j}\right)-P_{L j}\left(t, \mu_{P, L j}, L_{p e r}(t), \sigma_{P, L j}\right)=0
\end{aligned}
$$

(ii) Recursive reactive power balance equation

$$
\begin{aligned}
Q_{j-1}- & Q_{j}-x_{j}\left(\frac{\left(P_{j-1}^{2}+Q_{j-1}^{2}\right)}{V_{j-1}^{2}}\right)+Q_{p v, j}\left(t, \mu_{p v, j}, \theta_{p v, j}\right) \\
& +Q_{w, j}\left(t, \mu_{w, j}, \theta_{w j}\right)-Q_{L j}\left(t, \mu_{P, L j}, L_{p e r}(t), \sigma_{P, L j}\right)=0
\end{aligned}
$$

(iii) Recursive voltage equations

$$
V_{j+1}^{2}-V_{j}^{2}+2\left(r_{i} P_{i}+x_{i} Q_{i}\right)-\frac{1}{V_{j}^{2}}\left(r_{j}^{2}+x_{j}^{2}\right)\left(P_{j}^{2}+Q_{j}^{2}\right)=0
$$

(iv) Minimum and maximum limits of node voltages

$$
\left(V_{j}^{\min }\right)^{2} \leq V_{j}^{2} \leq\left(V_{j}^{\max }\right)^{2}
$$

(v) Operational limits on active power output from the solar PV generator

$$
\widehat{\mathrm{P}}_{p v, j}^{\min }\left(t, \mu_{p v, j}-\theta_{p v, j}\right) \leq \widehat{\mathrm{P}}_{p v, j}\left(t, \mu_{p v, j}, \theta_{p v, j}\right) \leq \widehat{\mathrm{P}}_{p v, j}^{\max }\left(t, \mu_{p v, j}+\theta_{p v, j}\right)
$$


(vi) Operational limits on active power output of from Wind Energy Generator (WEG)

$$
\widehat{\mathrm{P}}_{w, j}^{\min }\left(t, \mu_{w, j}-\theta_{w, j}\right) \leq \widehat{\mathrm{P}}_{w, j}\left(t, \mu_{w, j}, \theta_{w, j}\right) \leq \widehat{\mathrm{P}}_{w, j}^{\max }\left(t, \mu_{w, j}+\theta_{w, j}\right)
$$

(vii) Minimum and maximum limits of branch currents

$$
0 \leq I_{j k}=\sqrt{\left(\frac{\left(P_{j-1}^{2}+Q_{j-1}^{2}\right)}{V_{j-1}^{2}}\right)} \leq I_{j k}^{\max }
$$

(viii) Penetration limit of RERs in the system

$$
\begin{array}{r}
\sum_{\forall j} P_{p v, j}\left(t, \mu_{p v, j}, \theta_{p v, j}\right)+P_{w i n d, j}\left(t, \mu_{p v, j}, \theta_{w, j}\right) \\
\leq P n_{l i m} * \sum_{\forall j} P_{L, j}\left(t, \mu_{P, L, j} L_{p e r}(t), \sigma_{P, L, j}\right)
\end{array}
$$

(ix) Maximum penetration limit renewable power at each bus

$$
P_{p v, j}\left(t, \mu_{p v, j}, \theta_{p v, j}\right)+P_{w i n d, j}\left(t, \mu_{w, j}, \theta_{w, j}\right)=P_{D G, j, \max }
$$

\section{Modelling of Wind and Solar PV Energy Systems}

\subsection{Modeling of Power Output from Solar PV Generator}

The power output from solar PV panel depends not only on the specification but also on the environment. This variability is a function of solar irradiation on solar PV panel, and it can be modeled using a Weibull distribution function or Beta distribution function [18]. In this paper, the Beta distribution function is used. Using the historical data for location and time, the parameters of Beta model can be calculated by solving the following equations [19],

$$
\begin{aligned}
& \alpha=\mu\left(\frac{(1-\mu) \mu}{\sigma}-1\right) \\
& \beta=(1-\mu)\left(\frac{(1-\mu) \mu}{\sigma}-1\right)
\end{aligned}
$$

The corresponding probability density function (PDF) i.e., $\mathrm{f}(\mathrm{s})$ can be formulated as [19],

$$
\mathrm{f}\left(\mathrm{s}_{\mathrm{i}}\right)=\frac{\mathrm{s}\left(1-\mathrm{s}_{\mathrm{i}}\right)}{\Gamma(\alpha) \Gamma(\beta)} \Gamma(\alpha+\beta)
$$


The probability of solar irradiance during any specific hour is calculated using,

$$
P=\left[S=s_{i}\right]=\int_{s_{i, \min }}^{s_{i, \max }} f(\varsigma) \cdot d \varsigma
$$

The power output from the solar PV panel is given by,

$$
\left(P_{m p}\right)=\frac{\mathrm{s}}{s_{\text {ref }}} P_{m p, r e f}\left[1+\gamma\left(T-T_{r e f}\right)\right.
$$

\subsection{Modeling of Power Output from Wind Energy Generator (WEG)}

The wind speed distribution determines the performance and feasibility of wind power systems. Once the wind speed is known, the potential energy and power generated can be determined. The Weibull distribution function can be used to describe random behaviour of wind speed (v). The Weibull PDF is expressed as [20, 21],

$$
f(v)=\frac{\mathrm{k}}{\alpha}\left(\frac{\nu}{\alpha}\right)^{\mathrm{k}-1} \exp \left[\left(\frac{\nu}{\alpha}\right)^{\mathrm{k}}\right]
$$

where $\mathrm{v}>0, \mathrm{k}>0$ and $\alpha>0$. The factors $k$ and $\alpha$ are calculated using the mean wind speed $\left(V_{m}\right)$, and the standard deviations $(\sigma)$ as shown below,

$$
\begin{aligned}
\nu_{m} & =\frac{1}{n}\left\{\sum_{i=1}^{n} v_{i}\right\} \\
v & =\left[\frac{1}{n-1} \sum_{i=1}^{n}\left(v_{i}-v_{m}\right)^{2}\right]^{0.5} \\
\alpha & =\frac{v_{m}}{\Gamma\left(1+\frac{1}{k}\right)} \\
k & =\left(\frac{\sigma}{v_{m}}\right)^{-1.086}
\end{aligned}
$$

Figure 1 depicts the wind generator power output $\left(P_{W}\right)$ as a function of wind speed [20, 22].

The wind generator power output can be expressed as [23],

$$
P_{w}=\left\{\begin{array}{l}
0, \quad \mathrm{v} \leq \mathrm{v}_{\mathrm{ci}} \\
K_{1 \mathrm{v}}+K_{2 \mathrm{v}}, \quad \mathrm{v}_{\mathrm{ci}}<v<v_{\mathrm{r}} \text { and } P_{r}, \quad \mathrm{v}_{\mathrm{r}}<v<\mathrm{v}_{\mathrm{co}} \\
0, \quad v \geq \mathrm{v}_{\mathrm{co}}
\end{array}\right.
$$




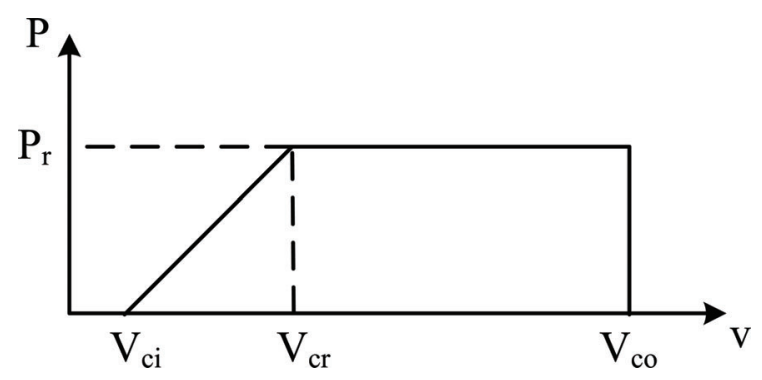

Figure 1 Wind power output as a function of wind speed.

where $K_{1}=\frac{P_{r}}{v_{r}-v_{c i}}$ and $K_{2}=-K_{1} v_{c i}$. The probability density function (PDF) can be expressed using [22, 24, 25],

$$
\begin{gathered}
P\left(P_{\omega, i}=0\right)=P\left(v_{0} \leq \nu<v_{c i}\right)+P\left(\nu_{c o} \leq \nu\right) \\
=\int_{v_{0}}^{v_{c i}} f(\nu) d \nu+\int_{\nu_{c o}}^{8} f(\nu) d \nu \\
P\left(0<P_{\omega, i} \leq P_{r}\right)=P\left(\nu_{c i} \leq \nu<v_{r}\right)=\int_{\nu_{c i}}^{\nu_{r}} f(v) d \nu \\
P\left(P_{\omega, i}=P_{r}\right)=P\left(v_{r} \leq \nu<v_{c o}\right)=\int_{v_{r}}^{v_{c 0}} f(v) d \nu
\end{gathered}
$$

\subsection{Uncertainty Modelling of Load Demand}

The uncertainty of load data is handled by utilizing Gaussian probability distribution functions (PDFs) for the modelling. Each load in the network is assumed to be a random variable distributed with parameters of mean and variance. The calculation of statistical mean of active and reactive power consumed is presented next:

Data sets may be artificially developed. For several systems, calculated or assumed data is provided which can be used instead of the statistical data set, if unavailable. The equations below summarize some sample values for the load modelling which have been used in probabilistic modelling studies.

$$
\begin{aligned}
\sigma_{P L, j}^{2} & =\frac{1}{m} \sum_{\forall m}\left(P_{L j, m}-\bar{P}_{L, j}\right) \\
\sigma_{P L, j}^{2} & =\frac{1}{m} \sum_{\forall m}\left(Q_{L j, m}-\bar{Q}_{L, j}\right)
\end{aligned}
$$




\section{S. S. Reddy}

The statistical data can be fit to the typical distribution curves to determine the most suitable distribution function and the parameters of the selected function. The variation of the load over the period of study is handled via consideration of the seasonal load variability patterns.

\section{Results and Discussion}

The modelled renewable energy resources (RERs), i.e., wind and solar energy systems and load demands are applied to the hybrid energy system considered in this paper. The proposed approach is tested on standard IEEE 37 node distribution system. Figure 2 depicts the IEEE 37 node distribution test system $[26,27]$. This test system is an actual feeder in California, with a $4.8 \mathrm{kV}$ operating voltage. It is characterized by delta configured, all line segments

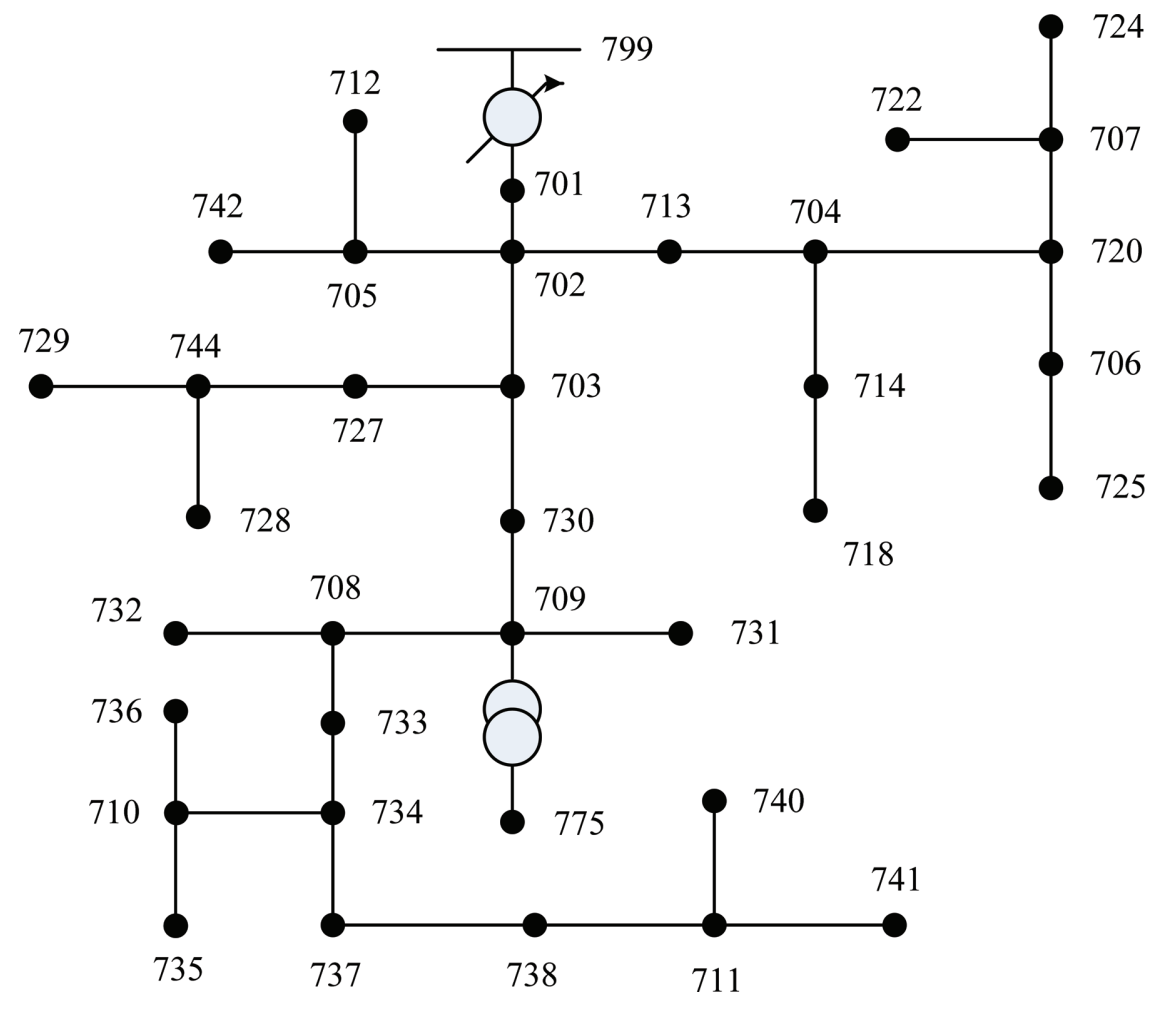

Figure 2 IEEE 37 node distribution test system. 
are underground, substation voltage regulation is two single-phase opendelta regulators, spot loads, and very unbalanced. The wind and solar PV systems with both MW and MVAr generating capabilities with variability and uncertainty of load are applied to the selected test system.

The proposed approach is coded in General Algebraic Modelling System (GAMS) [28], and it is solved using the CPLEX 11.2 solver (which is used to solve large scale Mixed Integer Linear Programming (MILP) problems). The optimization program is coded in a personal computer with Intel Core i7 processor of $2.8 \mathrm{GHz}$ and $8 \mathrm{~GB}$ RAM. For the WEG, the cutin $\left(\mathrm{v}_{i}\right)$, rated $\left(\mathrm{v}_{r}\right)$ and cut-out $\left(\mathrm{v}_{o}\right)$ wind speeds considered are 5, 15 and 45 miles/hour, respectively. Figures 3, 4 and 5 depicts the hourly solar irradiation, wind speed and load demand forecasts for the 24 hours scheduling period. Figure 6 depicts the hourly ambient temperature for the 24 hours scheduling period.

Table 1 presents the hourly generation schedules and total generation cost for the 24 hours period. The total amount of generation is $9813.97 \mathrm{MW}$ and the total generation cost for 24 hours period is $30995.13 \$$. From the above simulation results, it can be observed that the proposed approach efficiently handles the uncertainty of wind, solar PV and load demand forecasts.

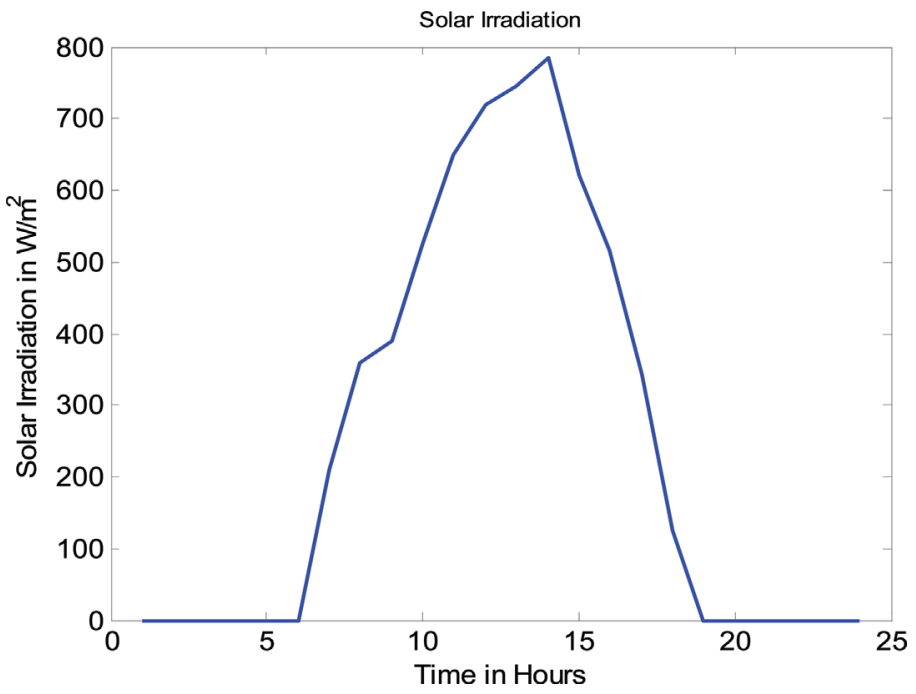

Figure 3 Hourly solar irradiation forecast for the 24 hours scheduling period. 
54 S. S. Reddy

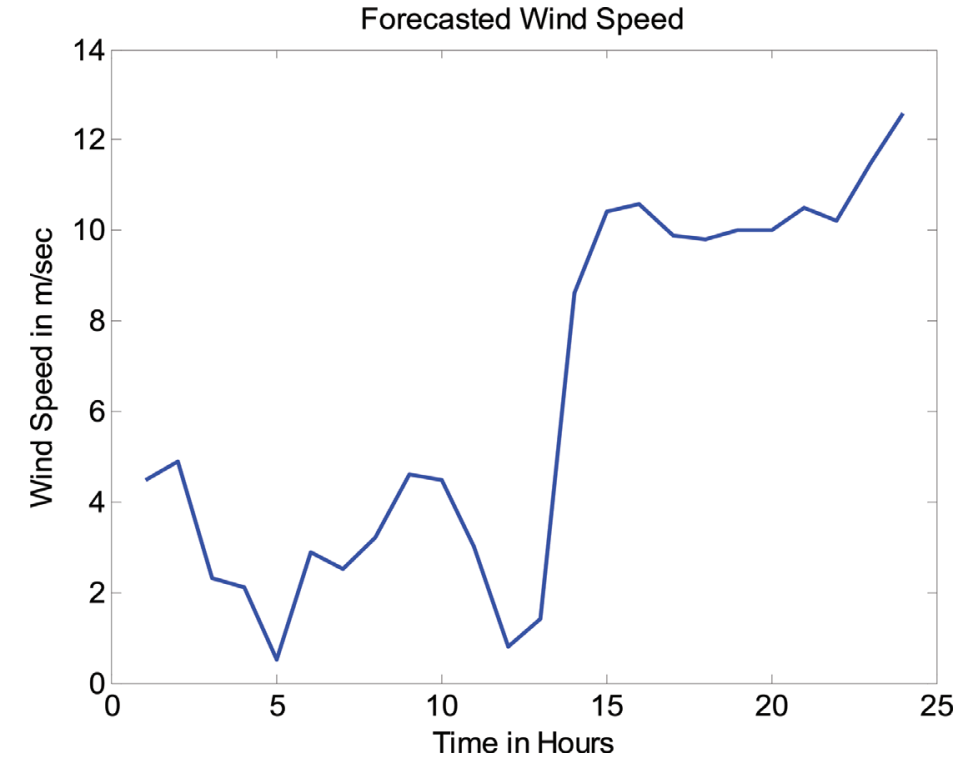

Figure 4 Hourly wind speed forecast for the 24 hours scheduling period.

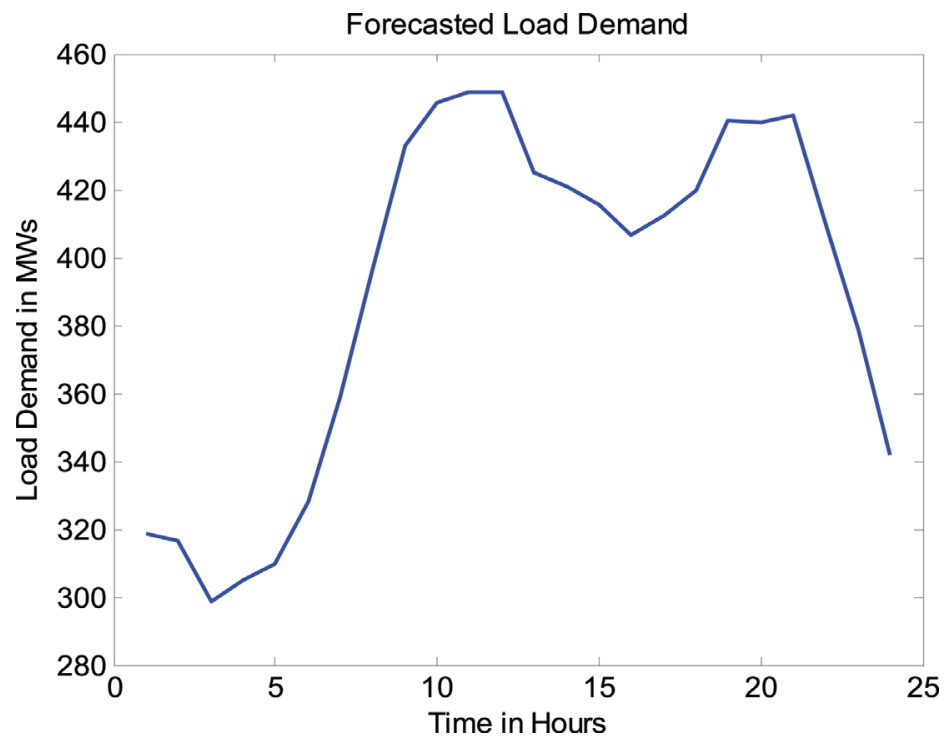

Figure 5 Hourly load demand forecast for the 24 hours scheduling period. 


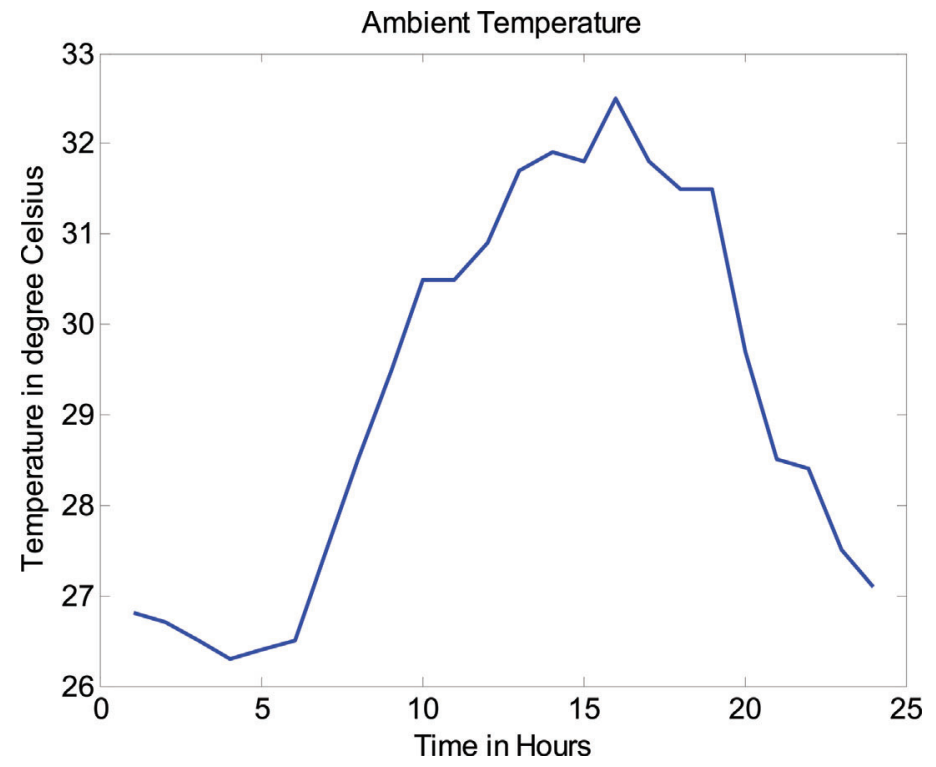

Figure 6 Hourly ambient temperature for the 24 hours scheduling period.

Table 1 Hourly generation schedules and total generation cost for 24 hours scheduling period

\begin{tabular}{lccccc}
\hline & $\begin{array}{c}\text { Hourly } \\
\text { Generation } \\
(\mathrm{MW})\end{array}$ & $\begin{array}{c}\text { Generation } \\
\text { Cost }(\$)\end{array}$ & Hour & $\begin{array}{c}\text { Hourly } \\
\text { Generation } \\
(\mathrm{MW})\end{array}$ & $\begin{array}{c}\text { Generation } \\
\text { Cost }(\$)\end{array}$ \\
\hline 1 & 334.2 & 1132.43 & 13 & 444.9 & 1374.51 \\
2 & 331.8 & 1121.05 & 14 & 441.4 & 1350.96 \\
3 & 312.9 & 1043.72 & 15 & 434.9 & 1325.14 \\
4 & 320.8 & 1093.41 & 16 & 425.9 & 1298.07 \\
5 & 325.8 & 1099.37 & 17 & 432.0 & 1341.10 \\
6 & 344.7 & 1173.9 & 18 & 439.8 & 1377.82 \\
7 & 376.0 & 1205.36 & 19 & 461.3 & 1396.45 \\
8 & 414.9 & 1317.93 & 20 & 461.1 & 1399.67 \\
9 & 453.4 & 1402.11 & 21 & 463.87 & 1401.0 \\
10 & 466.6 & 1409.32 & 22 & 431.1 & 1316.62 \\
11 & 469.9 & 1463.03 & 23 & 396.7 & 1278.84 \\
12 & 470.8 & 1480.14 & 24 & 359.2 & 1193.18 \\
\hline \multicolumn{7}{l}{ Total Generation $=9813.97 \mathrm{MW}$} \\
Total Generation Cost =30995.13\$
\end{tabular}




\section{Conclusions}

This paper proposed an approach which will help to address the variability of renewable energy resources (RERs) and uncertainties of load demands, which will help to improve system security, reliability, efficiency and reduce dependence on fossil fuels. The use of various probability density functions (PDFs) to represent the statistics of the resources is evaluated. This will benefit the stochastic scheduling and power management overtime for generation load adequacy and security. Also different optimization techniques are evaluated that will endorse the study of optimal strategy of resource allocation to meet load demand and ensure system security. Here, a robust stochastic approach with RERs and load demand is developed. This paper also modeled wind and solar to account for variability and obtain a stochastic power output. The effectiveness of the proposed approach has been tested on standard IEEE 37 node distribution system. From the simulation results, it can be observed that the proposed approach efficiently handles the uncertainty of wind, solar PV and load demand forecasts. Developing a methodology which can reflect the cost implications, reliability and cyber security of Smart Grid is a scope for future research work.

\section{References}

[1] Surender Reddy, S., and Momoh, J. A. (2016). "Minimum emission dispatch in an integrated thermal and wind energy conservation system using self-adaptive differential evolution," in Proceedings of the IEEE PES Power Africa Conference, June 28-July 2, 2016, Livingstone, 269-273.

[2] Feroldi, D., and Zumoffen, D. (2014). Sizing methodology for hybrid systems based on multiple renewable power sources integrated to the energy management strategy. Int. J. Hydrogen Energy 39, 8609-8620.

[3] Shaha, R., Kothari, D. P., and Chandrakar, V. S. (2016). "Optimization of renewable energy sources for hybrid power generation," in Proceedings of the Biennial International Conference on Power and Energy Systems: Towards Sustainable Energy, Bangalore, pp. 1-5, 2016.

[4] Bilil, H., Aniba, G., and Maaroufi, M. (2014). Multi-objective optimization of renewable energy penetration rate in power systems. Energy Proced. 50, 368-375.

[5] Nazir, R., Laksono, H. D., Waldi, E. P., Ekaputra, E., and Coveria, P. (2014). Renewable energy sources optimization: A micro-grid model design. Energy Proced. 52, 316-327. 
[6] Islam, A., Shahjahan, M. D., Khan, R. H., Kashem, A., and Babi, K. N. (2015). Feasibility study of renewable energy resources and optimization of hybrid energy system of some rural area in Bangladesh. Int. J. Phys. 3, 216-223.

[7] Amer, M., Namaane, A., and M'Sirdi, N. K. (2013). Optimization of hybrid renewable energy systems (HRES) using PSO for cost reduction. Energy Proced. 42, 318-327.

[8] Amusat, O. O., Shearing, P. R., and Fraga, E. S. (2016). Optimal integrated energy systems design incorporating variable renewable energy sources. Comput. Chem. Eng. 95, 21-37.

[9] Khare, V., Nema, S., and Baredar, P. (2016). Solar-wind hybrid renewable energy system: a review. Renew. Sustain. Energy Rev. 58, 23-33.

[10] Ikeda, S., and Ooka, R. (2016). A new optimization strategy for the operating schedule of energy systems under uncertainty of renewable energy sources and demand changes. Energy Build. 125, 75-85.

[11] Chen, J., and Garcia, H. E. (2016). Economic optimization of operations for hybrid energy systems under variable markets. Appl. Energy 177, $11-24$.

[12] Olatomiwa, L., Mekhilef, S., Ismail, M. S., and Moghavvemi, M. (2016). Energy management strategies in hybrid renewable energy systems: A review. Renew. Sustain. Energy Rev. 62, 821-835.

[13] Wang, X., and Palazoglu, A., El-Farra, N. H. (2015). Operational optimization and demand response of hybrid renewable energy systems. Appl. Energy, 143, 324-335.

[14] Sharafi, M., and ElMekkawy, T. Y. (2015). Stochastic optimization of hybrid renewable energy systems using sampling average method. Renew. Sustain. Energy Rev. 52, 1668-1679.

[15] Dai, R., and Mesbahi, M. (2013). Optimal power generation and load management for off-grid hybrid power systems with renewable sources via mixed-integer programming. Energy Conv. Manage. 73, 234-244.

[16] Singh, A. K., and Parida, S. K. (2015). A novel hybrid approach to allocate renewable energy sources in distribution system. Sustain. Energy Technol. Assess. 10, 1-11.

[17] Sinha, S., and Chandel, S. S. (2015). Review of recent trends in optimization techniques for solar photovoltaic-wind based hybrid energy systems. Renew. Sustain. Energy Rev. 50, 755-769.

[18] Reddy, S. S., Park, J. Y., and Jung, C. M. (2016). Optimal operation of microgrid using hybrid differential evolution and harmony search algorithm. Front. Energy 10, 355-362. 
[19] Momoh, J. A. (2012). Smart Grid Fundamentals of Design and Analysis. Hoboken, NJ: John Wiley.

[20] Liu, X., and Xu, W. (2010). Economic load dispatch constrained by wind power availability: a here-and-now approach. IEEE Trans. Sustain. Energy 1, 2-9.

[21] Reddy, S. S., Abhyankar, A. R., and Bijwe, P. R. (2012). "Market clearing for a wind-thermal power system incorporating wind generation and load forecast uncertainties," in Proceedings of the IEEE Power and Energy Society General Meeting, Jul. 22-26, San Diego, CA.

[22] Reddy, S. S., Bijwe, P. R., and Abhyankar, A. R. (2015). Joint energy and spinning reserves market clearing for wind-thermal power system incorporating wind generation and load forecast uncertainties. IEEE Syst. J. 9, 152-164.

[23] Wang, L., and Singh, C. (2007). "Genetic algorithm based adequacy evaluation of hybrid power generation system including wind turbine generators," in Proceedings of the International Conference on Intelligent Systems Applications to Power Systems, Toki Messe, 1-5.

[24] Hetzer, J., Yu, D. C., and Bhattarai, K. (2008). An economic dispatch model incorporating wind power. IEEE Trans. Energy Conv. 23, 603-611.

[25] Liu, X., and Xu, W. (2010). Minimum emission dispatch constrained by stochastic wind power availability and cost. IEEE Trans. Power Syst. 25, 1705-1713.

[26] Available at: http://www.itee.uq.edu.au/pssl/drupal7_with_innTheme/ sites/default/files/Test\%20system\%20report\%20(1).pdf

[27] Radial Distribution test feeders Available at: http://www.ewh.iee.org/ soc/pes/dsacom/testfeeders/index.html

[28] Available at: https://www.gams.com/download/ 


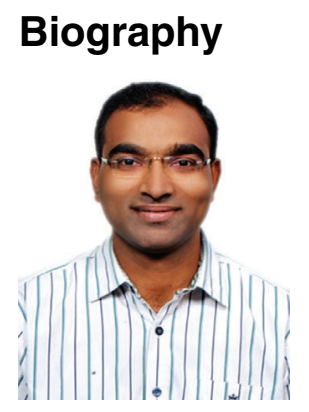

S. Surender Reddy received the Ph.D. degree in electrical engineering from the Indian Institute of Technology, New Delhi, India, in 2013. He was a Postdoctoral Researcher at Howard University, Washington, DC, USA, from 2013 to 2014. Currently, he is working as an Assistant Professor in the Department of Railroad and Electrical Engineering, Woosong University, Daejeon, Republic of Korea. His current research interests include power system restructuring issues, ancillary service pricing, real and reactive power pricing, congestion management, and market clearing, including renewable energy sources, demand response, smart grid development with integration of wind and solar photovoltaic energy sources, artificial intelligence applications in power systems, and power system analysis and optimization. 
